\title{
Up Close: Increasing Efforts in Materials Research at the Nuclear Research Center in Jülich
}

\author{
Bernd Stritzker \\ Note: This is the sixth article in a series focusing on the research capabilities and goals of interdisciplinary laboratories pursuing \\ materials research in universities, industry, and government.
}

The activities of the Nuclear Research Center Jülich (Kernforschungsanlage Jülich, KFA) comprise both basic and applied research in several areas. One of 13 national research facilities in the Federal Republic of Germany, KFA has a program designed to complement the general basic research efforts at universities and the more applied R\&D activities carried out by industry. Multidisciplinary research has been responsible for major achievements in the natural sciences, including nuclear medicine, nuclear chemistry, biotechnology, plasma physics/nuclear fusion, nuclear physics, and energy and environmental issues. These subjects will remain part of KFA's new research agenda. Particular attention will also be given to multiparticle systems and related solid-state research, surface research, and studies in vacuum physics. Problems associated with large-scale nonlinear systems will also be analyzed.

In addition to these activities, future research at KFA will focus on three major areas: materials development, environmental chemicals and ecosystems, and basic research on information technologies. The selection of this research focus reflects both historically evolved structures and the recognized need for KFA to respond to new and critical issues, especially in materials science.

\section{Materials Development}

The discovery of pioneering materials is not serendipitous. Rather, new materials and the techniques associated with their production result from intensive basic research. Accordingly, materials research at KFA seeks to develop new high-temperature materials and structural ceramics. The work builds on KFA's extensive experience in developing materials for the gascooled high-temperature reactor (HTR). Given the increasingly larger role being played by industry in developing the HTR, KFA can now concentrate on developing materials for general applications, such as high-temperature ceramics, fiber ceramics, and high-temperature components for engines, turbines, and ceramic coatings.

\section{Environmental Chemicals and Ecosystems}

The study of the flow of materials is central to the new program on Environmental Chemicals and Ecosystems, and will involve working closely with other large research facilities. Through the production of goods and the provision of services, large amounts of raw materials are converted into waste. A substantial part of these so-called material flows become emissions that enter atmospheric, aquatic, and terrestrial ecosystems and eventually make their way into the entire human food chain. Several KFA institutes share the task of investigating the pathway of these emissions, seeking to understand the associated chemical reactions and their environmental impacts.

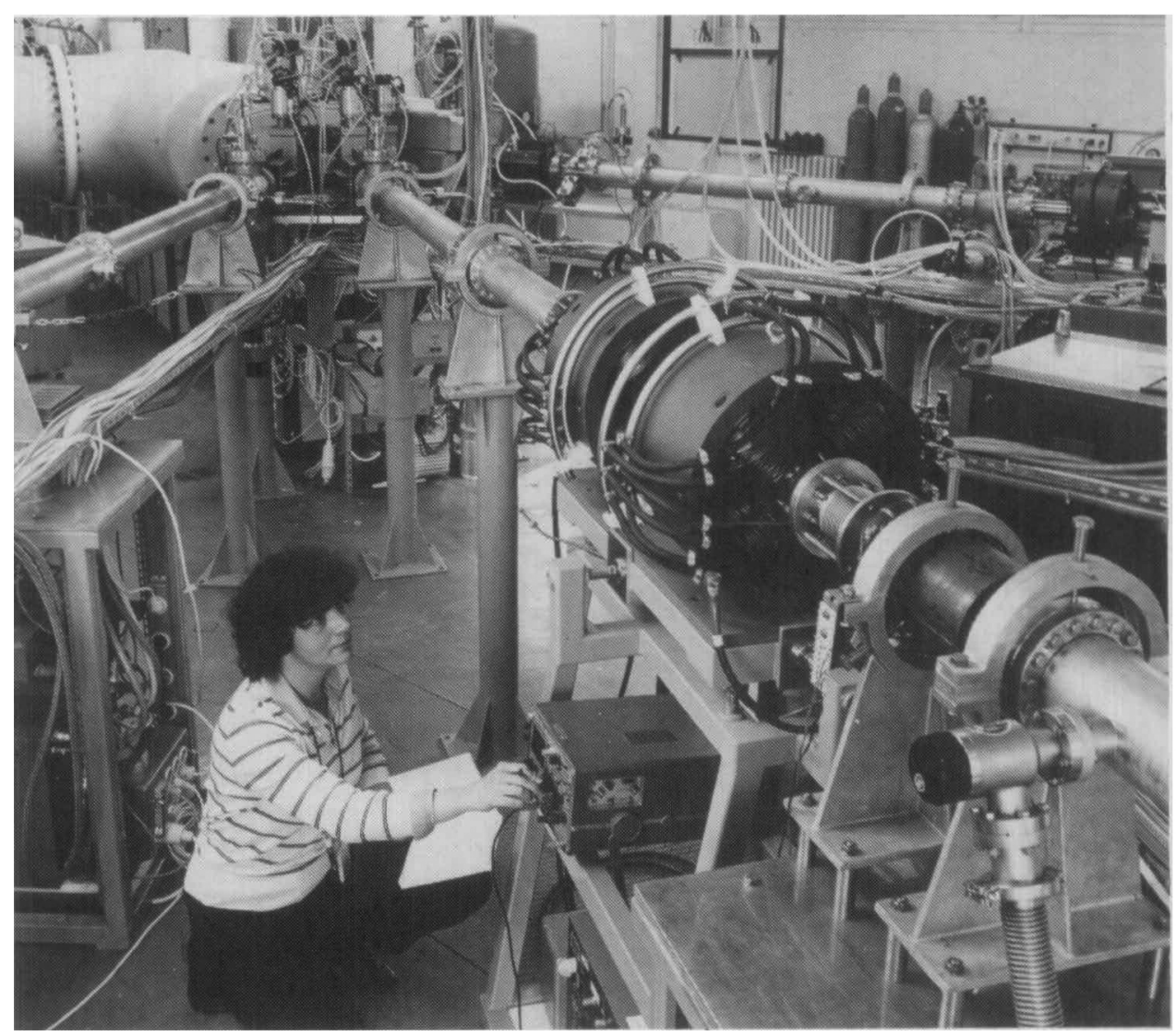

The 1.7 MV Tandetron accelerator at KFA Jülich is dedicated sor modification and analysis of near-surface regions by ion beams.

KFA has been studying environmental issues for several years. This research is now being extended to include problems associated with special hazardous wastes and theoretical ecology. Special hazardous wastes are defined as substances that by their very nature or by the scope of their use are detrimental to the well-being of human, atmospheric, and aquatic systems or are either explosive or combustible. The environmentally safe disposal of these wastes is a problem of increasing concern. The Institute of Chemical Technology, which has longstanding experience in treating nuclear waste, is exploring novel techniques for special waste disposal, including the suitable pretreatment of wastes.

Continued 
A working group on theoretical ecology will undertake basic studies to determine the quantitative levels at which certain chemicals become environmentally significant. Systems analyses, an integral part of KFA's work for many years, will be broadened to encompass issues associated with materials flows.

\section{Basic Research on Information Technologies}

The development of information technologies is expected to follow an accelerated pace. For an advanced industrial nation like the Federal Republic of Germany to remain competitive, it must have the capacity for the timely development and realistic marketing of modern information and communication technologies, as well as the materials associated with electronic components. KFA is responding to this need through a new research program titled Basic Research for Information Technology. The purpose is to investigate at the predevelopment stage the materials and structures needed for manufacturing the components of information technologies (e.g. new magnetic materials for data storage). Initial work in this area has been under way at the Institutes of Solid State Research and of Surface Research and Vacuum Physics. These efforts will be strengthened through the establishment of the Institute for Thin Film and Ion Technology, which emphasizes the application and development of modern techniques for preparing and characterizing surface alloys. There will be close collaboration with industry.

Near-term plans include extending these activities for research on advanced information processing and communication technologies. "Scientific computing" represents the third element, complementing theory and experimentation. The work will involve computer-aided simulation of technological processes and the development of parallel algorithms for supercomputers in close collaboration with two other German government laboratories (GMD, DESY).
All these KFA programs involve close working relations with universities and industry in the state of North Rhine-Westphalia. The so-called "Jülich model" is characteristic of this relationship, where heads of KFA research departments also hold a chair at one of the neighboring universities. The KFA has always attached major importance to transferring its research results to industry. Accordingly, it has established the Technology Transfer Office and a subsidiary, the Company for Integrated Exploration Systems (IES). The IES, which receives no government funding, explores hydrocarbon reserves (e.g. oil, natural gas). These transfer efforts will be intensified, particularly at the regional level.

\section{Bernd Stritzker}

Kernforschungsanlage Jülich Gmbh

Arbeitsgruppe Schichten- und

Ionentechnik

Postfach 1913

D-5170 Jülich, FRG

\title{
E-MRS SUMMER SCHOOL
}

\section{Nuclear Physics Applications in Materials Science}

\author{
NATO Advanced Study Institute \\ Viana do Castelo, Portugal \\ Seprember 6-18, 1987
}

\begin{abstract}
Nuclear Physics Applications in Materials Science will bring together scientists active in both ion beam modification of materials and hyperfine interactions in order to discuss technologically relevant results and stimulate new research in metals; bulk properties of semiconductors and insulators; and surfaces, interfaces, and thin films. The team of 15 lecturers from 9 countries has broad expertise.
\end{abstract}

For information, contact:

European-MRS
P. Siffert
Centre de Recherches Nucleaires
Laboratoire PHASE
67037 Strasbourg Cedex
France
Telephone (88) 286543

